\title{
Erratum to: Cyril Domb: A Personal View and Appreciation
}

\section{Michael E. Fisher}

Published online: 4 February 2012

(C) Springer Science+Business Media, LLC 2012

\section{Erratum to: J Stat Phys (2011) 145:510-517}

DOI 10.1007/s10955-011-0381-x

There are several mis-spellings in the article, Cyril Domb: A Personal View and Appreciation by Michael Fisher: Tony Guttman, should be spelled Tony Guttmann and Douglas Betts should be Donald Betts.

The online version of the original article can be found under doi:10.1007/s10955-011-0381-x. 